\title{
Tumor suppressor miR-24 restrains gastric cancer progression by downregulating RegIV
}

\author{
Yantao Duan ${ }^{\dagger}$, Lei Hư ${ }^{\dagger}$, Bing Liu, Beiqin Yu, Jianfang Li, Min Yan, Yingyan Yu, Chen Li, Liping Su, Zhenggang Zhu,
} Ming Xiang, Bingya Liu* and Qiumeng Yang*

\begin{abstract}
Background: microRNAs are small noncoding RNAs that modulate a variety of cellular processes by regulating multiple targets, which can promote or inhibit the development of malignant behaviors. Accumulating evidence suggests miR-24 plays important roles in human carcinogenesis. However, its precise biological role remains largely elusive. This study examined the role of miR-24 in gastric cancer (GC).

Methods: The expression of miR-24 in GC tissues compared with matched non-tumor tissues and GC cells was detected by qRT-PCR. Synthetic short single or double stranded RNA oligonucleotides and lentiviral vectors were used to regulate miR-24 expression in GC cells to investigate its function in vitro and in vivo.
\end{abstract}

Results: miR-24 was significantly downregulated in GC tissues compared with matched non-tumor tissues and was associated with tumor differentiation. Ectopic expression of miR-24 in SGC-7901 GC cells suppressed cell proliferation, migration and invasion in vitro as well as tumorigenicity in vivo by inducing cell cycle arrest in G0/G1 phase and promoting cell apoptosis. Furthermore, we identified RegIV as a target of miR-24 and demonstrated that miR-24 regulated RegIV expression via binding its $3^{\prime}$ untranslated region.

Conclusions: miR-24 functions as a novel tumor suppressor in GC and the anti-oncogenic activity may involve its inhibition of the target gene RegIV. These findings suggest the possibility for miR-24 as a therapeutic target in GC.

Keywords: miR-24, RegIV, Gastric cancer, Proliferation, Invasion, Metastasis

\section{Background}

Gastric cancer (GC) is one of the most common human cancers. Although the incidence and mortality have decreased worldwide over the past 20 years, GC still ranks as the fourth most common and the second most lethal cancer worldwide [1]. Although research in GC has made great progress, the molecular mechanisms underlying GC still have not been fully elucidated.

MicroRNAs (miRNAs) are small noncoding, doublestranded RNA molecules that can modulate the expression of target genes by influencing the post-transcriptional processes regulating gene expression. miRNAs recognize target mRNAs based on complete or incomplete sequence complementarity and prevent the production of protein

\footnotetext{
*Correspondence: byliu@sjtu.edu.cn; yangqiumeng@hotmail.com ${ }^{\dagger}$ Equal contributors

Shanghai Key Laboratory of Gastric Neoplasms, Department of Surgery, Shanghai Institute of Digestive Surgery, Ruijin Hospital, Shanghai Jiao Tong University School of Medicine, No 197 Ruijin er Road, Shanghai 200025, People's Republic of China
}

by binding to the $3^{\prime}$ untranslated region (UTR) or the open reading frame (ORF) of target mRNA [2,3]. miRNAs have been demonstrated to function in cellular proliferation and differentiation processes, including the epithelial-mesenchymal transition [4] and endodermal differentiation of human embryonic stem cells [5]. In addition to general cellular functions of miRNA, these molecules also play important roles in a variety of human diseases. Multiple studies have shown that the misregulation of miRNAs is related with cancer [6,7], in which they function as either oncogenes or tumor suppressors. miRNAs have been reported to be involved in acute myeloid leukemia, breast cancer, non-small cell lung carcinoma, hepatocellular carcinoma, colon cancer, GC and other cancers [8-13]. Overexpression or downregulation of miRNAs leads to diversification of protein expression, therefore contributing to tumorigenesis by modulating proliferation, angiogenesis and invasion. Researchers found that miRNA expression profiles can 
be used to classify human cancers, and this finding was prior to the use of messenger RNA profiles for classification of poorly differentiated tumors $[14,15]$.

Aberrant expression of specific miRNAs in GC has been previously reported and was correlated with the progression and prognosis of GC [16-18]. We previously found that miR-24, which can serve as a tumor suppressor through a target site polymorphism [19], was a significantly downregulated miRNA in GC cells and tissues compared with non-tumor tissues. In this study, we analyzed miR-24 expression levels in GC tissues compared with matched non-tumor tissues, and assessed correlations between miR-24 level and clinicopathologic parameters. We evaluated the influence of overexpression of miR-24 on the growth and apoptosis of SGC-7901 GC cells both in vitro and in vivo. We also determined the biological effect of downregulation of miR-24 expression on GC cells. Furthermore, we identified RegIV (regenerating islet-derived family, member 4) as one of the target genes of miR-24. We hypothesize that miR-24 can regulate the invasion and metastasis of GC cells by directly targeting the RegIV gene.

\section{Results}

\section{Overexpression of miR-24 inhibits GC cell proliferation}

To explore the expression of miR-24 in GC, quantitative real-time RT-PCR (qRT-PCR) was performed. Expression of miR-24 was generally downregulated in nine GC cell lines compared with the immortalized normal gastric mucosal epithelial cell GES-1 (Figure 1A). Expression of miR-24 was examined further with qRT-PCR in tumor tissues and matched non-tumor tissues from $63 \mathrm{GC}$ patients (Figure 1B). The average expression level of miR-24 was significantly downregulated in tumor tissues compared to matched non-tumor tissues (Figure 1C). Together, these results provided strong evidence that miR24 was significantly downregulated in GC.

We next examined the correlations between expression level of miR-24 and clinicopathologic factors in human GC. The clinical and pathologic characteristics of $63 \mathrm{GC}$ patients are provided in Table 1. Based on relative expression ratios of miR-24/U6 $=1$, the cases were divided into two groups: the miR-24 high-expression group $(\mathrm{n}=29)$ and the miR-24 low-expression group $(\mathrm{n}=34)$. The miR-24 low-expression group exhibited significantly lower tumor differentiation $(\mathrm{P}=0.021)$. However, the miR-24 expression level did not show any relationship with age, gender, tumor site, the depth of local invasion, lymph node metastasis, or TNM stage.

To investigate the biological function of miR-24 in development and progression of $\mathrm{GC}$, we transfected SGC-7901 cells with miR-24 mimics (SGC-7901/miR-24) or miR-24 inhibitor (SGC-7901/anti-miR-24). As shown in Additional file 1: Figure S1A and S1B, we selected
$100 \mathrm{nM}$ as suitable concentration in subsequent experiments. Ectopic expression of miR-24 in SGC-7901 cells was confirmed by qRT-PCR. Next, we examined cell proliferation by WST assay. Overexpression of miR-24 inhibited the growth rate of SGC-7901 cells compared with miR-control transfected cells $(\mathrm{P}<0.05)$, whereas anti-miR-24 increased cell growth activities $(\mathrm{P}<0.05$, Figure 1D).

\section{Overexpression of miR-24 inhibits the migration and invasion of GC cells}

Next we evaluated the effect of miR-24 on cell migration and invasion in GC. Cell migration and invasion assays showed that overexpression of miR-24 suppressed cell migration (SGC-7901/miR-24 group, 63.0 \pm 3.6 cells per field; control group, $126.3 \pm 7.0$ cells per field; $\mathrm{P}<0.05$ ) and invasion (SGC-7901/miR-24 group, $34.7 \pm 2.1$ cells per field; control group, $63.7 \pm 3.5$ cells per field; $\mathrm{P}<0.05$ ) (Figure $2 \mathrm{~A}, \mathrm{~B}$ ). In contrast, knockdown of miR-24 significantly increased cell migration (SGC-7901/anti-miR-24 group, 182.3 \pm 5.0 cells per field; control group, $105.3 \pm 3.8$ cells per field; $\mathrm{P}<0.01$ ) and invasion (SGC-7901/anti-miR-24 group, 124.3 \pm 3.8 cells per field; control group, $62.7 \pm 2.5$ per field; $\mathrm{P}<0.01$ ) (Figure $2 \mathrm{~A}, \mathrm{C}$ ).

\section{Overexpression of miR-24 promotes the apoptosis of GC cells and induces cell cycle arrest in G0/G1 phase}

Given that observed cellular growth may be affected by the rates of apoptosis and cell cycle progression, we examined the effects of miR-24 on apoptosis and cell cycle in vivo by flow cytometry. We found that approximately $12-15 \%$ of SGC-7901/miR-24 cells exhibited morphologic features typical of apoptosis, including condensed chromatin and nuclear fragmentation by Hoechst 33342 staining for DNA content. In contrast, after accounting for the rare spontaneous apoptosis in SGC-7901 cells, the SGC-7901/anti-miR-24 group did not show any significant changes by Hoechst33342 staining (Figure 3A). Flow cytometry showed that the apoptotic rate was significantly increased in SGC-7901/miR-24 cells compared with control cells $(13.62 \% \pm 1.25 \%$ vs. $6.15 \% \pm 0.95 \%$, respectively; $\mathrm{P}<0.01$ ), and significantly decreased in SGC$7901 /$ anti-miR-24 compared with controls $(3.92 \% \pm 0.52 \%$ vs. $6.35 \% \pm 0.83 \%$, respectively; $\mathrm{P}<0.05$ ) (Figure $3 \mathrm{~B}, \mathrm{D}$ ).

To further elucidate the mechanism of miR-24-mediated growth inhibition of GC cells, cell cycle analysis was performed (Figure 3C,E). Upon upregulation of miR-24, the percentage of cells in G0/G1 phase increased from $40.51 \% \pm 3.15 \%$ in controls to $72.24 \% \pm 3.65 \%(\mathrm{P}<0.01)$, while knockdown miR-24 reduced the percentage of cells in G0/G1 phase from $42.35 \% \pm 2.78 \%$ in controls to $30.25 \% \pm 1.25 \%(\mathrm{P}<0.05)$. 


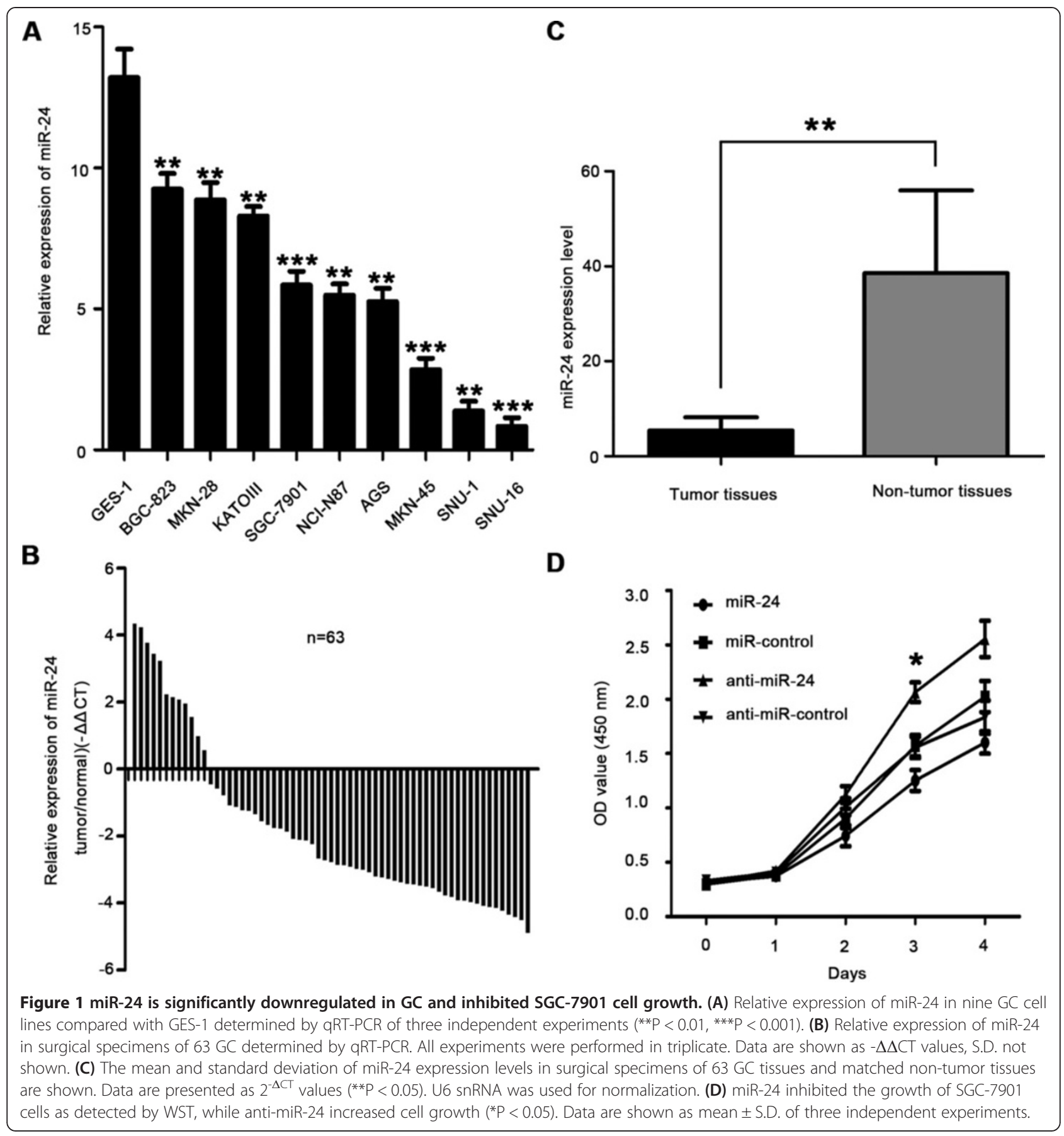

RegIV is a target gene of miR-24

To more closely examine the mechanisms of miR-24 in GC, we searched for candidate target genes by bioinformatics. TargetScan, miRBase Tatget and StarBase were applied to search for potential targets of miR-24. Among the predicted targets, RegIV was identified as one of the target genes of miR-24, and we identified one potential miR-24 binding site within its 3'UTR (Figure 4A). Next, we examined the expression of RegIV in nine GC cells and GES-1. We found that RegIV was overexpressed in nine
GC cells compared with GES-1, and exhibited an inverse expression pattern compared with miR-24 (Additional file 2: Figure S2A and S2B). To investigate whether the 3'UTR of RegIV mRNA was a functional target of miR24 , luciferase reporter gene assays were performed. We first evaluated the activity of miR-24 (or miR-control) co-transfected into SGC-7901 cells with Luc-RegIV plasmid or the Luc-RegIV-mut plasmid (in which the putative miR-24 binding site was mutated), along with the pRL-TK plasmid containing the Renilla luciferase 
Table 1 Relationship between miR-24 expression level and clinicopathologic variables in $63 \mathrm{GC}$ patients

\begin{tabular}{|c|c|c|c|}
\hline \multirow{2}{*}{$\begin{array}{l}\text { Clinicopathologic } \\
\text { parameters }\end{array}$} & \multicolumn{2}{|c|}{ miR-24 expression } & \multirow{2}{*}{$\begin{array}{l}P \\
\text { value }\end{array}$} \\
\hline & High $(n=29)$ & Low $(n=34)$ & \\
\hline \multicolumn{4}{|l|}{ Gender } \\
\hline Male & 17 & 21 & 0.799 \\
\hline Female & 12 & 13 & \\
\hline \multicolumn{4}{|l|}{ Age (years) } \\
\hline$<60$ & 15 & 18 & 0.923 \\
\hline$\geq 60$ & 14 & 16 & \\
\hline \multicolumn{4}{|l|}{ Tumor location } \\
\hline Distal third & 8 & 8 & 0.310 \\
\hline Middle third & 6 & 13 & \\
\hline Proximal third & 15 & 13 & \\
\hline \multicolumn{4}{|l|}{ WHO classification } \\
\hline Adenocarcinoma & 25 & 28 & 0.155 \\
\hline Signet-ring cell carcinoma & 1 & 5 & \\
\hline Mucinous adenocarcinoma & 3 & 1 & \\
\hline \multicolumn{4}{|l|}{ Differentiation } \\
\hline Well, moderately & 15 & 8 & 0.021 \\
\hline Poorly & 14 & 26 & \\
\hline \multicolumn{4}{|l|}{ Borrmann classification } \\
\hline |/II & 11 & 12 & 0.828 \\
\hline III/IV & 18 & 22 & \\
\hline \multicolumn{4}{|l|}{ Local invasion } \\
\hline $\mathrm{T} 1 / \mathrm{T} 2$ & 1 & 7 & 0.098 \\
\hline $\mathrm{T} 3 / \mathrm{T} 4$ & 28 & 27 & \\
\hline \multicolumn{4}{|l|}{ Lymph node metastasis } \\
\hline No & 6 & 4 & 0.535 \\
\hline Yes & 23 & 30 & \\
\hline \multicolumn{4}{|l|}{ Distant metastasis } \\
\hline No & 28 & 31 & 0.724 \\
\hline Yes & 1 & 3 & \\
\hline \multicolumn{4}{|l|}{ TNM stage } \\
\hline$|/| \mid$ & 7 & 8 & 0.955 \\
\hline III/IV & 22 & 26 & \\
\hline
\end{tabular}

gene as an internal control (Figure 4B). Cells co-transfected with miR-24 demonstrated a significant decrease of luciferase activity compared with the miR-control group $(\mathrm{P}<0.05)$. However, miR-24 co-transfected with the Luc-RegIV-mut plasmid showed no significant difference in reporter activity compared with cells co-transfected with miR-control. Likewise, anti-miR-24 increased the luciferase activity of wild-type Luc-RegIV, but had no effect on Luc-RegIV-mut plasmid (Figure 4C; P < 0.05). We also performed luciferase reporter gene assays in
SNU-16 to minimize the influence of endogenous miR24. At first, ectopic expression of miR-24 in SNU-16 cells was confirmed by qRT-PCR. Expression of miR-24 transfected with miR-24 mimics was about 50 times higher than that of miR-control group in SNU-16 $(\mathrm{P}<0.01)$, while no statistical difference with the transfection of anti-miR-24 (Additional file 3: Figure S3A). Cells co-transfected with miR-24 demonstrated a significant decrease of luciferase activity compared with the miR-control group $(\mathrm{P}<$ 0.001), while no statistical difference with anti-miR-24 transfection (Additional file 3: Figure S3B and S3C). These results strongly indicated that the 3'UTR of RegIV contains direct binding sites for miR-24.

Next we examined miR-24 regulation of RegIV mRNA and protein levels in transfected SGC-7901 cells. ELISA analysis showed that RegIV protein levels were greatly suppressed in SGC-7901/miR-24 cells, whereas RegIV protein levels were upregulated in SGC-7901/anti-miR-24 cells (Figure 4D; ${ }^{*} \mathrm{P}<0.05$, ${ }^{* *} \mathrm{P}<0.01$ ). qRT-PCR analysis indicated no difference in the level of RegIV mRNA in all transfected cell groups (Figure 4E; $\mathrm{P}>0.05$ ). Meanwhile, we detected the expression of c-MYC in GC cells as positive control transfected with miR-24 [20]. We found that miR-24 downregulated RegIV and c-MYC (Additional file 4: Figure S4A and S4B).

Previous studies demonstrated that RegIV was associated with proliferation and metastasis of GC. We next used immunohistochemical analysis to evaluate the expression of RegIV in GC. Our findings confirmed overexpression of RegIV in GC. The protein level of RegIV in normal gastric mucosa was lower than intestinal metaplasia of stomach and gastric signet-ring cell carcinoma (Figure $4 \mathrm{~F}-\mathrm{H}$ ). To assess the clinical relevance of these findings, we examined the correlation between the expressions of RegIV and miR-24 in GC tissues. We found that RegIV and miR-24 exhibited an inverse expression pattern in GC tissues (Table 2). These results support the notion that downregulation of miR-24 resulted in increased protein levels of RegIV in GC.

\section{Overexpression of miR-24 inhibits tumorigenicity in vivo}

Given that miR-24 improved the proliferation of GC cells in vitro, we examined whether miR-24 could affect tumorigenicity in vivo. Retrovirus-mediated SGC-7901/ miR-24 and SGC-7901/miR-control stable cell lines were obtained as described in the Methods section. SGC-7901/RV-miR-24 and SGC-7901/RV-miR-control cells were injected subcutaneously into four-week-old male nude mice, and tumor formation was monitored. Tumors grew slower in the SGC-7901/RV-miR-24 group than those in the SGC-7901/RV-miR-control group (Figure 5A). The average tumor volume in mice inoculated with SGC-7901/ RV-miR-24 cells at day 28 was significantly smaller compared to mice inoculated with SGC-7901/RV-miR-control 


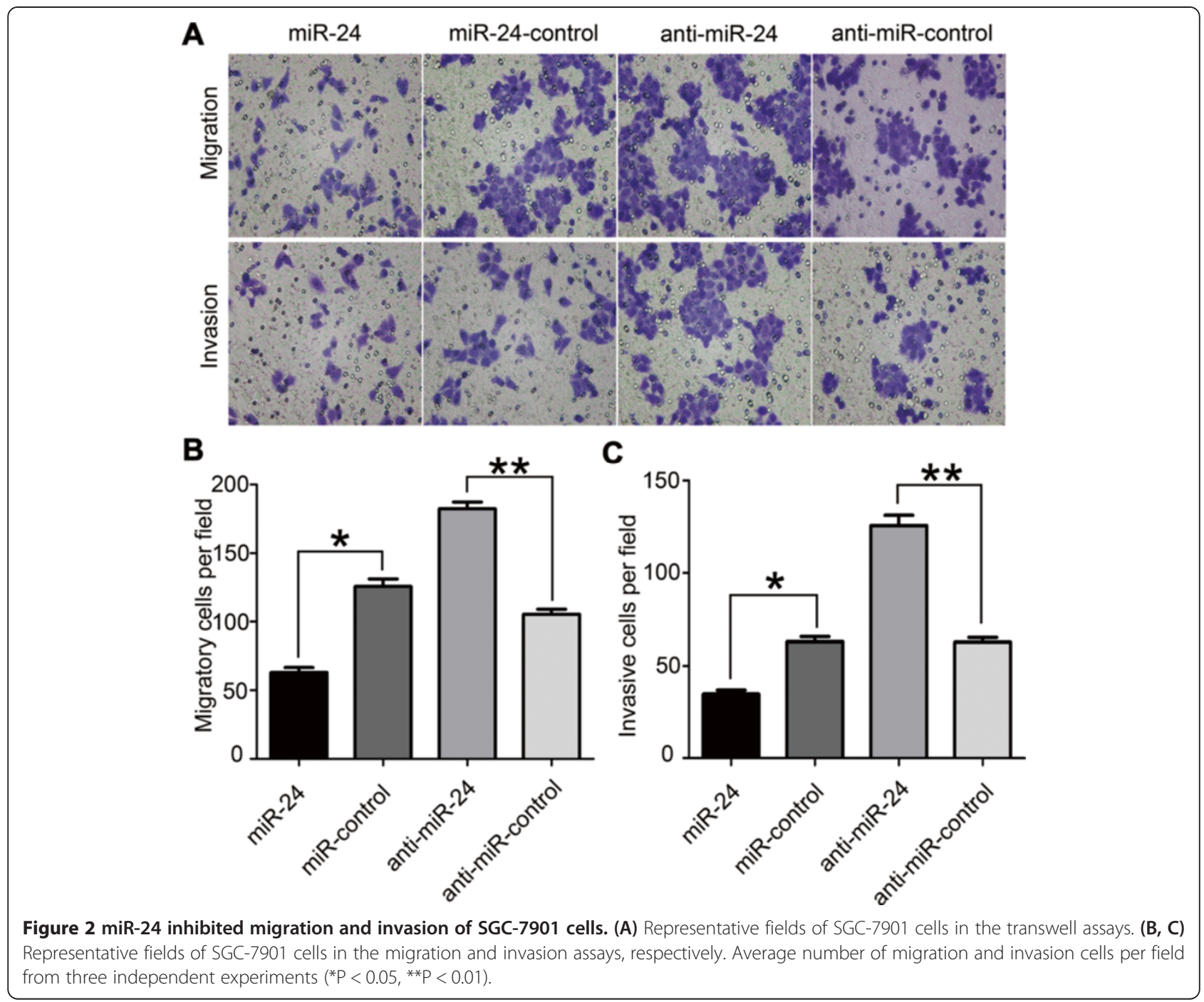

cells $\left(397.45 \pm 93.07 \mathrm{~mm}^{3}\right.$ vs. $1083.56 \pm 101.56 \mathrm{~mm}^{3}$, respectively) (Figure $5 \mathrm{~B}$ and $\mathrm{C}$; $\mathrm{P}<0.05$ ).

To assess whether tumor growth inhibition in SGC7901/RV-miR-24 cells was partly due to the suppression of proliferation, immunohistochemical analyses of tumor tissues were performed. As shown with Ki-67 antigen staining, the decreased tumor growth in mice injected with SGC-7901/RV-miR-24 cells may be partially because of lower proliferation caused by the overexpression of miR-24. The percentage of Ki-67-antigen-positive cells was lower in the tumor derived from SGC-7901/RV-miR24 cells than the tumor derived from SGC-7901/RV-miRcontrol cells $(37.1 \% \pm 3.6 \%$ vs. $79.5 \% \pm 5.2 \%$, respectively) (Figure 5D and E; P $<0.01$ ). The expression level of RegIV as determined by ELISA was lower in the tumor derived from cells overexpressing miR-24 than the tumor derived from control cells $(1.77 \pm 0.15 \mathrm{ng} / \mathrm{ml}$ in SGC-7901/RV$\mathrm{miR}-24$ vs. $3.13 \pm 0.25 \mathrm{ng} / \mathrm{ml}$ in SGC-7901/RV-miRcontrol) (Figure 5F; $\mathrm{P}<0.05$ ). However, there was no statistical difference in the relative expression of RegIV mRNA (Figure 5G). Therefore, the tumorigenicity of SGC7901/RV-miR-24 cells were significantly reduced in vivo.

\section{Discussion}

Accumulating evidence has supported important roles for miRNAs, which act either as tumor suppressors or oncogenes, in GC [21-23]. In addition, many miRNAs have been shown to exhibit therapeutic potential. Because of their function as master regulators of the genome and novel mechanism of action, miRNAs are considered a promising technology for therapeutic development [24]. miR-26a has antitumorigenic properties and potential therapeutic utility for liver cancer in vitro and in vivo, and was associated with rapid and sustained inhibition of cancer cell proliferation and highly specific induction of tumor cell death [25]. The specific mechanism of the roles of dysregulated miRNAs in gastric carcinogenesis remains elusive. 

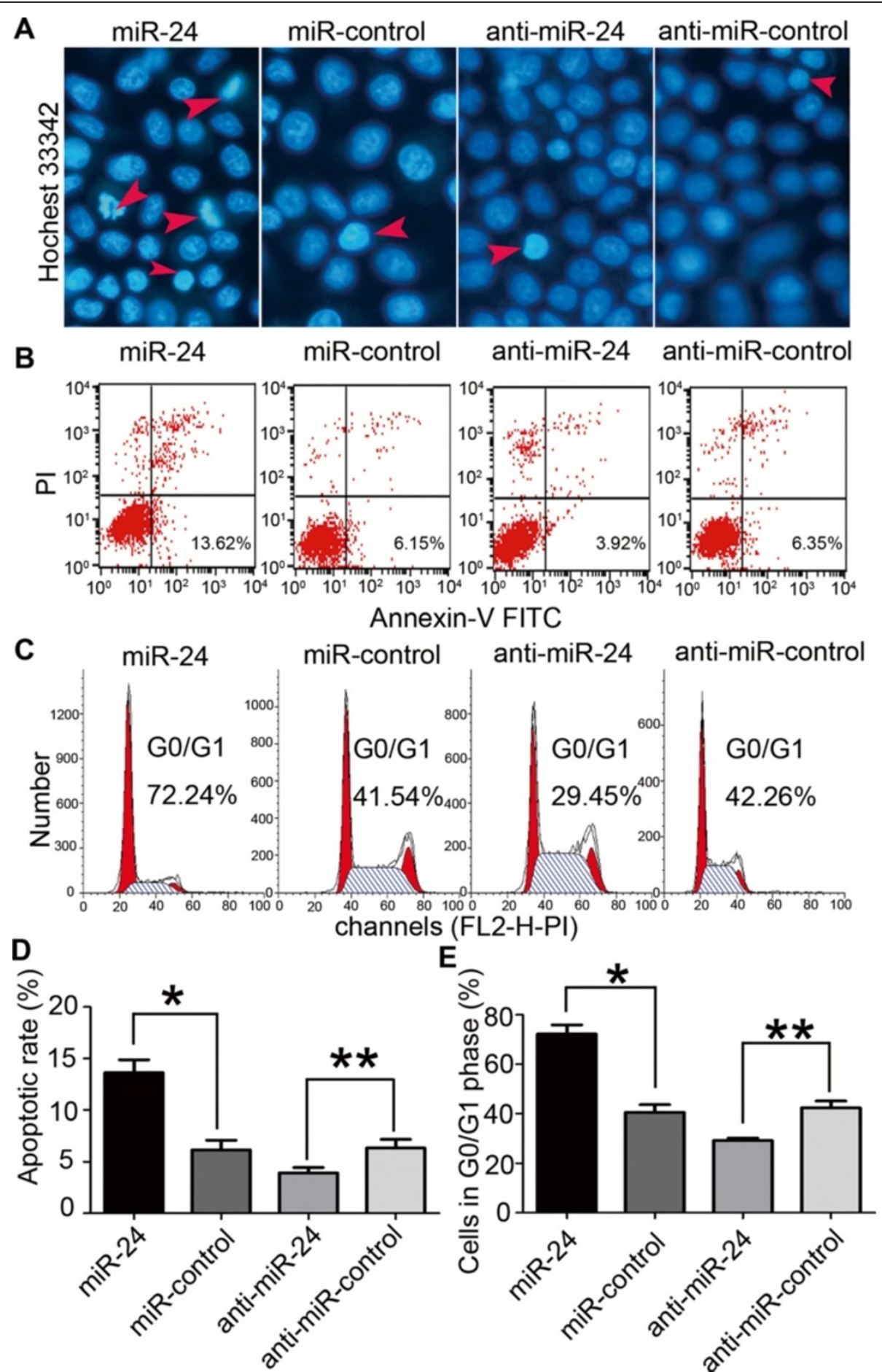

Figure 3 miR-24 induced cell apoptosis and G0/G1 cell cycle arrest. (A) Representative histograms depicting nuclear morphology of SGC-7901 cells transiently transfected with 100 nM miR-24 mimics or inhibitor and their respective controls (Hoechst33342 staining, original magnification 400X). (B) Representative histograms depicting apoptosis of SGC-7901 cells transiently transfected with 100 nM miR-24 mimics or inhibitor and their respective controls. (C) Representative histograms depicting cell cycle of SGC-7901 cells transiently transfected with $100 \mathrm{nM}$ miR-24 mimics or inhibitor and their respective controls. (D, E) The percentage of apoptotic and G0/G1 phase cells of three independent experiments, mean \pm S.D. $\left({ }^{*} \mathrm{P}<0.05,{ }^{* *} \mathrm{P}<0.01\right)$. 


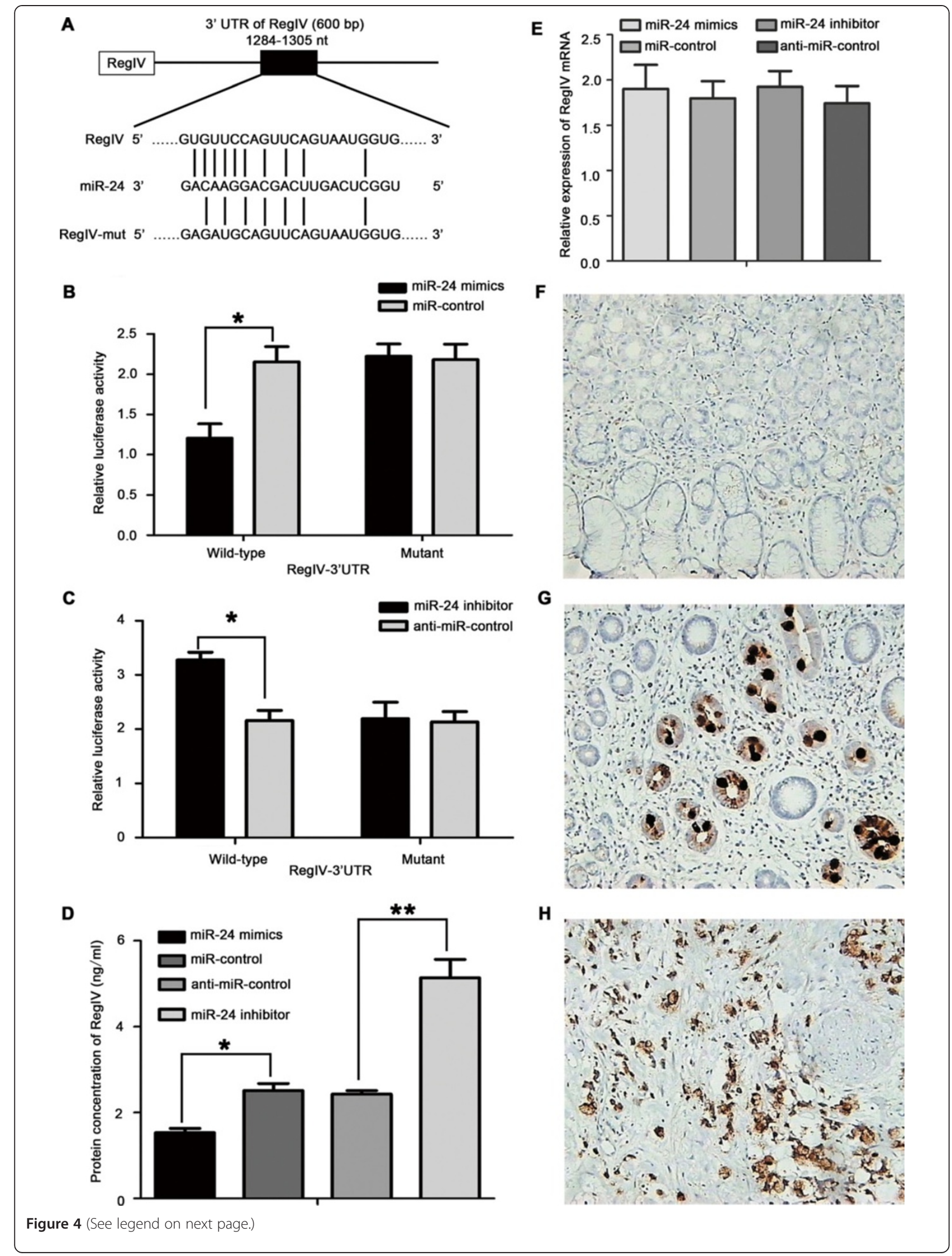




\section{(See figure on previous page.)}

Figure 4 miR-24 targeted the 3'UTR of RegIV gene and immunostaining of RegIV in gastric tissues. (A) Schematic graph of the putative binding sites of miR-24 in the RegIV 3'UTR. RegIV-mut indicates the RegIV-3'UTR with mutation in miR-24-binding sites. (B) miR-24 mimics downregulated activity of a luciferase reporter containing wild-type RegIV $3^{\prime} U T R{ }^{*} P<0.05$ ), but not the reporter with mutant RegIV $3^{\prime} U T R$. (C) Anti-miR-24 increased the luciferase activity of wild-type Luc-RegIV ( ${ }^{*} P<0.05$ ), but had no effect on the mutant. (D) Forty-eight hours after miR-24 mimic and control transfection of SGC-7901 cells, the protein level of RegIV was significantly decreased compared with the miR-control as determined by ELISA. Anti-miR-24 increased the expression of RegIV compared with the anti-miR-control $\left({ }^{*} P<0.05\right.$, **P $\left.<0.01\right)$. (E) Twenty-four hours after miR-24 mimic or inhibitor and the respective control transfection in SGC-7901 cells, there was no difference in the mRNA level of RegIV compared with the miR-control as determined by qRT-PCR (P>0.05). Data are shown as mean \pm S.D. of three independent experiments. (F) No expression of RegIV was detected in normal gastric mucosa. (G) ReglV was expressed in intestinal metaplasia of stomach. (H) Strong expression of RegIV was observed in gastric signet-ring cell carcinoma.

In this study, we demonstrated the inhibitory effects of miR-24 on tumor metastasis at the clinical, cellular and molecular level and in an experimental animal model. We provided detailed mechanistic experimental evidence for the role of miR-24 in GC by suppressing the expression of RegIV. Studies showed that miR-24 may act as oncogene in malignant effusions [26], oral carcinoma $[27,28]$, prostate cancer [3] and lung cancer [29,30], but may act as a tumor suppressor in colon cancer [19] and retinoblastoma tumors [31]. Lal A et al. found that miR24 inhibited cell proliferation and cell cycle progression by suppressing the expression of E2F2, MYC and other cell cycle regulatory genes by binding to "seedless" 3" UTR miRNA recognition elements [20]. Wu J et al. reported that transfection of miR-24 into GC cells reduced the expression of AE1 protein, which resulted in inhibiting cellular proliferation [32]. However, the complete underlying mechanisms for miR-24 in GC are still not clear.

Our report identified miR-24 as a candidate tumor suppressor in GC. We found downregulation of miR-24 expression both in GC tissues and cell lines. Overexpression of miR-24 in SGC-7901 GC cells significantly reduced proliferation and invasion both in vitro and in vivo, revealing the potential therapeutic effect of miR24 in GC. The opposite result was obtained when the expression of miR-24 was inhibited by anti-miR-24. Together these results suggest that miR-24 may function as a tumor suppressor in human GC.

miRNAs bind to perfect or imperfect complementary "seed" sequences in target mRNAs, leading to cleavage

Table 2 RegIV and miR-24 exhibit inverse expression pattern in GC

\begin{tabular}{llll}
\hline & \multicolumn{2}{c}{ miR-24 expression } & P value \\
\cline { 2 - 3 } & Low & High & \\
\hline Reg IV $(I H C)$ & & 16 & $0.038^{*}$ \\
Negative & 9 & 13 & \\
Positive & 25 & 13 & \\
\hline
\end{tabular}

${ }^{*} P<0.05$ was considered statistically significant. of target mRNAs or inhibition of their translation [33]. In this study, we identified RegIV as a target gene of miR-24. miR-24 bound with incomplete complementarity to RegIV mRNA, resulting in direct translational inhibition of RegIV mRNA but with no effect on overall mRNA stability. As the different action modes of miRNA, miR-24 did not affect the mRNA level of RegIV but the translational inhibition. RegIV is a member of the human Reg gene family, which shares sequence similarity with the carbohydratebinding domain of C-type lectins, and was first isolated and characterized in human inflammatory bowel disease [34]. RegIV is one type of secreted proteins, and plays a biological role depending on the extracellular secreted proteins, so that we took ELISA as a preferred detection method. Western blot was also performed to validate the protein level of RegIV, and we obtained the similar results. Previous studies have reported that the RegIV gene was frequently overexpressed in GC and is potentially involved in invasion, metastasis, and carcinogenesis of GC. RegIV expression was narrowly restricted in noncancerous tissues $[35,36]$. RegIV expression was markedly higher in patients with peritoneal metastasis compared to those without peritoneal metastasis. RegIV might accelerate peritoneal metastasis in GC and levels in lavage fluids could serve as a good marker for peritoneal metastasis [37-39]. RegIV may function as a serum biomarker for GC patients and inhibits 5FU-induced apoptosis by induction of Bcl-2 and dihydropyrimidine dehydrogenase [40].

In the current study, we identified miR-24 as a potential upstream regulator of RegIV. First, overexpression of miR-24 decreased the activity of a luciferase reporter gene containing the 3'UTR of RegIV, while mutation of the "seed region" sites in the 3'UTR of RegIV abolished the regulatory effect of miR-24. The opposite result was obtained when we used anti-miR-24. Second, human GC tissues expressed significantly lower levels of miR-24 than non-tumor tissues, while GC tissues contain significantly higher levels of RegIV protein than non-tumor tissues. Third, overexpression of miR-24 downregulated RegIV at the protein level, while downregulation of miR- 

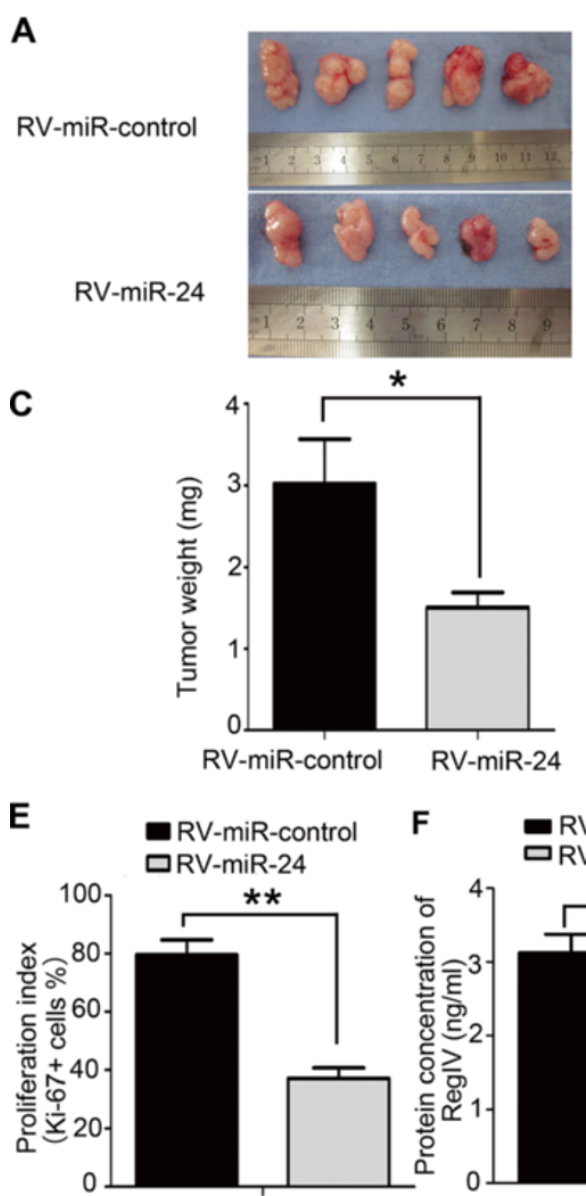

Figure 5 miR-24 inhibited tumorigenicity and proliferation in vivo. (A) Photograph of tumors derived from RV-miR-24 or RV-miR-control cells in nude mice. (B) Growth kinetics of tumors in nude mice. Tumor diameters were measured every 7 days. The volume of the nude mice indicated by bars, S.D. $\left({ }^{*} P<0.05\right)$. (C) The average weight of tumors in nude mice. Data are shown as means \pm S.D. ( $\left.{ }^{*} P<0.05\right)$. (D) Representative photographs of immunohistochemical analysis of Ki-67 antigen in tumors of nude mice (original magnification, 200X). (E) Representative proliferative index of tumors in RV-miR-24 and RV-miR-control nude mice. Data are shown as means \pm S.D. $\left.{ }^{* * P}<0.05\right)$. (F) Expression levels of ReglV in tumor tissues of nude mice. Data are shown as means \pm S.D. $\left({ }^{*} P<0.05\right)$. (G) Expression levels of RegIV mRNA in tumor tissues of nude mice $(P>0.05)$. Data are shown as mean \pm S.D. of three independent experiments.

24 increased RegIV protein level. Fourth, overexpression of miR-24 was significantly related with proliferation and metastasis, indicating a functional overlap with RegIV. All these results indicate that RegIV might be a direct target gene of miR-24 in GC.

Carcinogenesis is a series of sequential events, including detachment, migration, local invasion, angiogenesis, intravasation, survival in the circulatory system, extravasation and regrowth in different organs $[41,42]$. Here we showed that miR-24 could regulate the carcinogenesis of GC through modulating proliferation, migration and local invasion. Furthermore, our evidence suggests the possibility for miR-24 as a therapeutic target in GC. Further studies are required to fully understand the detailed mechanisms of miR-24 in GC carcinogenesis and as a potential therapeutic approach.
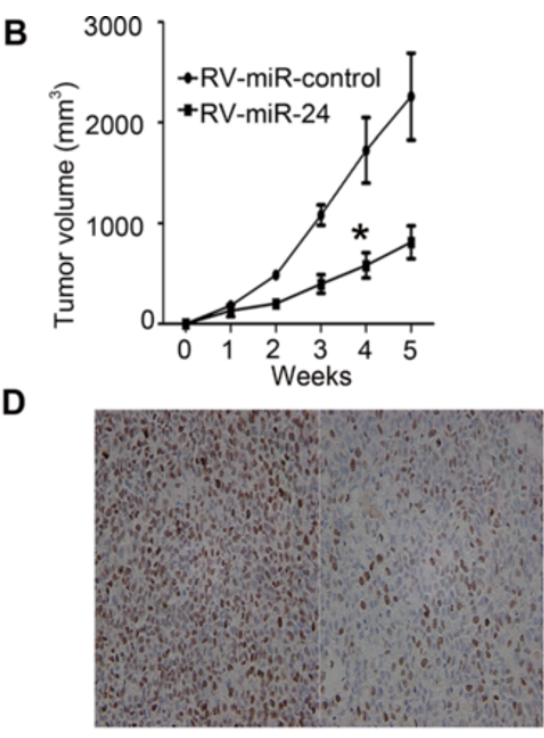

RV-miR-control RV-miR-24
G RV-miR-control

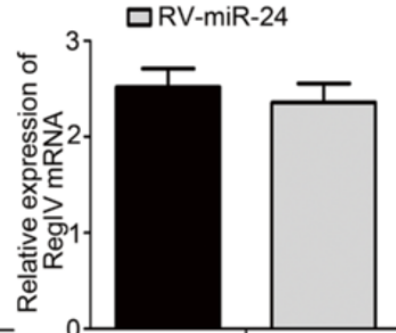


MKN-28, BGC-823, MKN-45, and AGS were purchased from Shanghai Institutes for Biological Sciences, Chinese Academy of Sciences. The immortalized normal gastric mucosal epithelial cell line (GES-1) was a gift from Prof. Feng Bi (Huaxi Medical University, Chengdu, Sichuan Province, PR China). The embryonic kidney cell line $293 \mathrm{~T}$ was preserved in our laboratory and maintained in Dulbecco's modified Eagle's medium (DMEM) with $10 \%$ fetal bovine serum (FBS) at $37^{\circ} \mathrm{C}$ in a humidified atmosphere with $5 \% \mathrm{CO}_{2}$. All GC cells were cultured in RPMI 1640 supplemented with $10 \%$ FBS in a humidified incubator with $5 \% \mathrm{CO}_{2}$ at $37^{\circ} \mathrm{C}$.

\section{Tissue samples}

Primary cancer tissues and paired adjacent non-tumor tissues were collected from patients with GC underwent radical gastrectomy at the Department of Surgery, Ruijin Hospital, Shanghai Jiao Tong University School of Medicine. The adjacent normal tissues were obtained over $5 \mathrm{~cm}$ from the primary cancer. Tissue samples were immediately snap-frozen in liquid nitrogen and stored in a refrigerator at $-80^{\circ} \mathrm{C}$. Tissues for immunohistochemistry were fixed in $4 \%$ paraformaldehyde and paraffinembedded. Clinicopathological data were reviewed, and TNM staging classification was based on criteria of American Joint Committee on Cancer (AJCC, 6th edition). All samples were verified by pathological examination.

\section{RNA isolation and qRT-PCR}

Total RNA was isolated from tissue samples and cell lines using Trizol reagent (Invitrogen, Carlsbad, CA, USA) according to the manufacturer's instructions. The expression levels of miRNAs were evaluated using the Hairpin-itTM miRNAs qPCR Quantitation Kit (GenePharma, Shanghai, PR China) following the manufacturer's protocol. The U6 small nuclear RNA (RNU6B; GenePharma) was used for normalization. The relative expression ratio of miR-24 in each paired tumor and non-tumor tissue was calculated using the $2^{-\Delta \Delta C T}$ method. The miR-24 expression level was defined as upregulated when the relative expression ratio was $>1$, and defined as downregulated when the relative expression ratio was $<1$. The expression level of RegIV and c-MYC mRNA was measured by qRT-PCR according to the instructions of the $\mathrm{SYBR}^{\bullet}$ Green PCR Master Mix (Applied Biosystems, Foster City, CA, USA). The primers for RegIV were 5' - CACGACCCACAGAAGAGGCAGC -3' (forward) and 5' - GGCGCTTGTTGCATTCGTTGCT -3' (reverse). Primers for c-MYC were $5^{\prime}$ - TCTTCCCC TACCCTCTCAACGA -3' (forward) and 5' - TTCCT CATCTTCTTGTTCCTCCTCA -3' (reverse). Primers for GAPDH were 5'- GGACCTGACCTGCCGTCTA G $-3^{\prime}$ (forward) and 5' - GTAGCCCAGGATGCCCT
TGA - 3' (reverse) according to the human RegIV, c-MYC and GAPDH cDNA sequences in GenBank. The GAPDH mRNA level was used for normalization. PCRs of each sample were conducted in triplicate.

\section{Transient transfection}

The hsa-miR-24 mimics (miR-24), negative control (miR-control), hsa-miR-24 inhibitor (anti-miR-24) and inhibitor negative control (anti-miR-control) oligonucleotides were purchased from GenePharma. Cells in logarithmic growth phase were trypsinized, counted, and seeded in 6-well plates to ensure 50\% cell confluence on the next day for transfection. Transfection of cells with oligonucleotides was performed using Lipofectamine ${ }^{\mathrm{TM}}$ 2000 Reagent in line with the manufacturer's instructions (Invitrogen) at a final concentration of $100 \mathrm{nM}$.

\section{ELISA}

ELISA (Cusabio, Wuhan, China) analysis of RegIV was performed $48 \mathrm{~h}$ post-transfection with miR-24 oligonucleotides. The culture supernatants were collected, and the secreted RegIV level was quantified by ELISA according to the manufacturer's protocol. The expression of RegIV in tumor tissues was detected by ELISA.

\section{Cell proliferation assay}

SGC-7901 cells proliferation was measured by the colorimetric water-soluble tetrazolium salt (WST) assay with a Cell Counting Kit- 8 according to the manufacturer's instructions (Dojindo, Kumamoto, Japan). The cells were seeded in 96-well plates $\left(2 \times 10^{3}\right.$ cells/well $)$ $24 \mathrm{~h}$ post-transfection, and cell proliferation was examined every $24 \mathrm{~h}$ for 5 days. The number of viable cells was determined by measurement of the optical density difference between $450 \mathrm{~nm}$ and $600 \mathrm{~nm}$ using a Safire ${ }^{2}$ microplate reader (Tecan, Switzerland). All experiments were performed in triplicate.

\section{Migration and invasion assay}

Migration assays were performed using the $6.5 \mathrm{~mm}$ Transwell ${ }^{\oplus}$ with $8.0 \mu \mathrm{m}$ Pore Polycarbonate Membrane Insert (Corning, New York, USA) according to the manufacturer's instructions. At $24 \mathrm{~h}$ post-transfection with miR-24 mimics, inhibitors and controls (100 nM), SGC7901 cells were incubated in serum-free medium for $24 \mathrm{~h}$, and then $3 \times 10^{4}$ cells in $200 \mu \mathrm{l}$ serum-free medium were added to the upper chamber. A volume of $500 \mu \mathrm{l}$ of $10 \%$ FBS-containing medium was then added to the lower chamber as a chemoattractant. Cells were incubated for another $36 \mathrm{~h}$ at $37^{\circ} \mathrm{C}$, and then non-migrating cells on the upper surface of the membrane were gently scraped off with cotton swabs. Cells that migrated to the bottom of the membrane were stained with the cell stain provided in the assay kit for 20 min and visualized under 
a microscope. To minimize the bias, at least three randomly selected fields with 200x magnification were counted, and the average number was taken.

For the invasion assay, $6.5 \mathrm{~mm}$ Transwell ${ }^{\circ}$ with $8.0 \mu \mathrm{m}$ Pore Polycarbonate Membrane Insert (Corning) was used according to the manufacturer's instructions and matrigel (BD Biosciences, USA) was used to simulate the extracellular matrix in vivo. Briefly, $3 \times 10^{4}$ SGC7901 cells in $200 \mu \mathrm{l}$ serum-free medium were added to the upper chamber pre-coated with matrigel gel. Then, $500 \mu \mathrm{l}$ of $10 \%$ FBS-containing medium was added to the lower chamber as a chemo-attractant. Cells were incubated for $48 \mathrm{~h}$ at $37^{\circ} \mathrm{C}$, and then non-invading cells were removed with cotton swabs. Invasive cells were fixed, stained with $0.04 \%$ crystal violet and counted as described above.

\section{Apoptosis and cell cycle analysis}

At $48 \mathrm{~h}$ post-transfection, cells were collected by trypsinization and washed with PBS. For apoptosis analysis, cells were resuspended in Binding Buffer (Annexin V-FITC Apoptosis Detection Kit I, BD Pharmingen, USA) at a concentration of $1 \times 10^{6}$ cells $/ \mathrm{ml}$. Next, $2.5 \mu \mathrm{l}$ of FITC AnnexinV and $5 \mu \mathrm{l}$ PI (BD Pharmingen) were added to $100 \mu \mathrm{l}$ of the cell suspension. After incubation for $15 \mathrm{~min}$ in the dark at room temperature, $400 \mu 1$ binding buffer was added. Apoptosis was analyzed by flow cytometry (FACSCalibur, Becton Dickinson) using Cell Quest software (Becton Dickinson). Annexin V-FITCpositive and PI-negative cells were detected as undergoing apoptosis.

For cell cycle analysis, the cells were fixed with $70 \%$ ethanol and stored at $4^{\circ} \mathrm{C}$ overnight. The following day, the fixed cells were washed with PBS, treated with $2 \mu \mathrm{l}$ of RNase A $(50 \mu \mathrm{g} / \mathrm{ml})$, and stained with $20 \mu \mathrm{l}$ of Propidium Iodide $(50 \mu \mathrm{g} / \mathrm{ml})$ for $30 \mathrm{~min}$ in the dark at $37^{\circ} \mathrm{C}$, with rocking every $5 \mathrm{~min}$. The stained cells were analyzed by flow cytometry (FACSCalibur). At least 10000 cells in each sample were analyzed to obtain a measurable signal.

For examining nuclear morphology associated with apoptosis, cells were washed in PBS and incubated with a DNA dye, Hoechst33342 (Beyotime, Nantong, PR China), according to the protocol of the kit. The staining was visualized under a fluorescent microscope that was excited at a wavelength of $350 \mathrm{~nm}$ and measured at $460 \mathrm{~nm}$.

\section{Construction of the RegIV 3'UTR reporter gene system}

A $600 \mathrm{bp}$ fragment of the wild-type (WT) RegIV-3'UTR or mutant RegIV-3'UTR (mut) containing the putative miR-24 binding site was synthesized by RT-PCR. The wild-type RegIV-3'UTR was synthesized using the following sequences: 5 ' - ggactagtagcaagaatcaagattctgc taact $-3^{\prime}$ (forward) and $5^{\prime}$ - cgacgcgttgggtgtatttcttg gtcttatttc $-3^{\prime}$ (reverse). The mutant RegIV-3'UTR was designed to mutate three intermittent nucleotides complementary to the miR-24 seed region. The mutant sequences were as follows: $5^{\prime}$ - gaggttgctgagatgcagttcag taatggtgaatgtggaa $-3^{\prime}$ (forward) and $5^{\prime}$ - ttccacattcaccattactgaactggaacacagcaacctc $-3^{\prime}$ (reverse). After digestion with SpeI and MluI, the wild-type and mutant RegIV-3' UTR fragments were cloned into the SpeI and MluI sites of the pMIR-Report luciferase vector (Applied Biosystems) and named pMIR/RegIV and pMIR/RegIV/ mut, respectively. Proper insertion was confirmed by sequencing. SGC-7901 cells were seeded in 24-well plates. At $24 \mathrm{~h}$ later, cells were transfected with $200 \mathrm{ng}$ of either $\mathrm{pMIR} / \operatorname{RegIV}$ or $\mathrm{pMIR} /$ RegIV/mut, together with $2 \mathrm{ng}$ of the pRL-TK vector (Promega, Madison, WI, USA) containing Renilla luciferase and $60 \mathrm{pmol}$ of the miR-24 mimic, inhibitor or control. Transfection was performed using Lipofectamine ${ }^{\text {tw }} 2000$ (Invitrogen) and Opti-MEM I reduced serum medium. Cells were harvested $48 \mathrm{~h}$ post-transfection. Firefly and Renilla luciferase activities were measured by using a dualluciferase reporter assay (Promega) according to the manufacturer's protocol. Firefly luciferase activity was normalized to Renilla luciferase activity.

\section{Western blot analysis}

Cells were lysed in RIPA buffer in the presence of Protease Inhibitor Cocktail (Pierce, Rockford, USA). Protein was quantified by a BCA Protein Assay Kit (Pierce, Rockford, USA). Protein (60 ug) was separated by $10 \%$ sodium dodecyl sulfate polyacrylamide gel electrophoresis, and transferred onto polyvinylidene fluoride membranes. The membranes were blocked with $5 \%$ non-fat milk in Tris-buffered saline and then incubated with primary antibodies at $4^{\circ} \mathrm{C}$ overnight. The primary antibodies used were anti-RegIV (1:1000; Abcam, USA), anti-c-MYC (1:500; Santa Cruz Biotechnology, Inc., USA) and anti- $\beta$-actin (1:5000; Abcam, USA). Membranes were then washed three times in TBST solution for 10 min each time, and then incubated with secondary antibodies. Signals were detected by an enhanced chemiluminescence detection system (Amersham Bioscience, Piscataway, NJ, USA) as the manufacturer's protocol.

\section{Immunohistochemistry}

Paraffin sections, $4 \mu \mathrm{m}$ in thickness, were baked for $1 \mathrm{~h}$ at $68^{\circ} \mathrm{C}$. After deparaffinization and rehydration, antigen retrieval was performed by boiling in $10 \mathrm{mmol} / \mathrm{l}$ of citrate buffer ( $\mathrm{pH}$ 6.0) for $10 \mathrm{~min}$. After inhibition of endogenous peroxidase activity for $30 \mathrm{~min}$ with methanol containing $0.3 \% \mathrm{H}_{2} \mathrm{O}_{2}$, the sections were blocked with $2 \%$ bovine serum albumin in PBS for $30 \mathrm{~min}$ and incubated with mouse anti-human RegIV monoclonal 
antibody (Abcam, Hong Kong; dilution 1:150). The immune complex was visualized by the Dako REAL ${ }^{\mathrm{ma}} \mathrm{En}$ Vision $^{\mathrm{mm}}$ Detection System, Peroxidase/DAB, Rabbit/ Mouse (Dako, Denmark), according to the manufacturer's procedures. The nuclei were counterstained with hematoxylin.

\section{Retroviral transfection for stable cell lines}

The genomic region that included the primary transcript of miR-24 was cloned into the EcoRI-XhoI site of the modified pMSCV-GW-RfA-PGK-EGFP retroviral vector. Negative control vectors had no insert. For each cultured $293 \mathrm{~T}$ plate $(10 \mathrm{~cm})$, a plasmid mixture containing $10 \mu \mathrm{g}$ of miR-24 retroviral vector, $10 \mu \mathrm{g}$ of gag/pol vector and $10 \mu \mathrm{g}$ of VSVG vector was co-transfected with $90 \mu$ FuGENE6 transfection reagent (Roche, Basel, Switzerland) added directly to $0.6 \mathrm{ml}$ of serum-free medium. The plasmid/medium/FuGENE6 mix was added drop-wise to the $293 \mathrm{~T}$ plate. After $12 \mathrm{~h}, 15 \mathrm{ml}$ viral collection medium was added to the transfected cells. We then harvested the virus twice a day for two days. Infections of SGC-7901 cells were performed in the presence of $8 \mu \mathrm{g} / \mathrm{mL}$ of polybrene in each well of a 6-well plate. SGC-7901 cells were spin infected at $1500 \mathrm{rpm}$ for $0.5 \mathrm{~h}$ at room temperature and the virus-containing supernatant was removed after $2 \mathrm{~h}$. Positive cells were selected by GFP expression by FACS and named as RV-miR-24 or RV-miR-control. Expression of miR-24 was confirmed by qRT-PCR.

\section{Tumor xenograft model}

A total volume of $100 \mu \mathrm{l}$ of cells $\left(2 \times 10^{6}\right.$ cells $)$ transfected with RV-miR-24 or RV-miR-control were inoculated subcutaneously into 4-week-old male nude mice (Institute of Zoology, Chinese Academy of Sciences, Shanghai, China). Mice were checked weekly, and tumor nodules were measured with a caliper. Tumor volume was evaluated using the following formula: volume $=($ width + length) $/ 2 \times$ width $\times$ length $\times 0.5236$. Tumor growth curves and inhibiting rates were calculated. The two experimental groups were sacrificed after 5 weeks. All tumor grafts were excised, weighed, harvested, fixed, and embedded. The mouse-anti-human Ki-67 antigen monoclonal antibody (Dako, dilution 1:50) was used to determine nuclear expression of Ki-67 antigen with immunohistochemistry procedures and samples were observed using a Nikon microscope (Nikon, Japan). The proliferative index (PI) score was measured by the mean percentage of nuclei staining positive for Ki-67 antigen in 1000 cells.

\section{Statistical analysis}

The relationship between miR-24 expression level and clinicopathologic parameters was explored by the Pearson $X^{2}$ test. The differences between groups were analyzed using Student $t$ test when there were only two groups, or assessed by one-way ANOVA when there were more than two groups. All statistical analyses were performed using the SPSS 16.0 software. A two-tailed value of $P<0.05$ was considered statistically significant.

\section{Additional files}

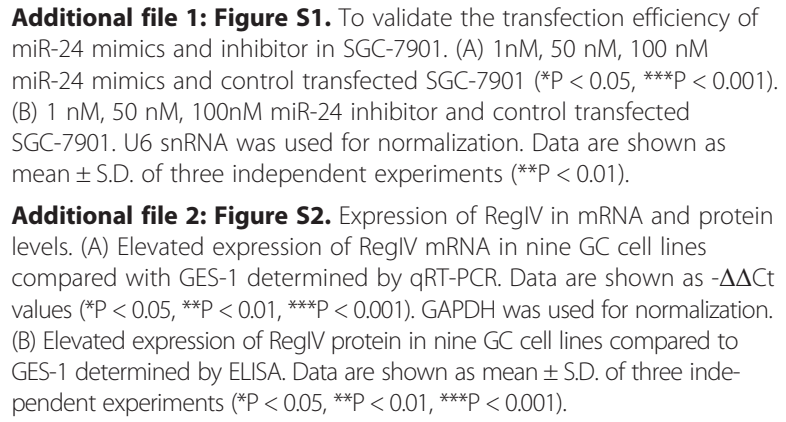

Additional file 1: Figure S1. To validate the transfection efficiency of miR-24 mimics and inhibitor in SGC-7901. (A) 1nM, 50 nM, $100 \mathrm{nM}$ miR-24 mimics and control transfected SGC-7901 ( ${ }^{*} P<0.05$, ***P $\left.<0.001\right)$. (B) $1 \mathrm{nM}, 50 \mathrm{nM}, 100 \mathrm{nM}$ miR-24 inhibitor and control transfected SGC-7901. U6 snRNA was used for normalization. Data are shown as mean \pm S.D. of three independent experiments ( ${ }^{*} P<0.01$ ).

Additional file 2: Figure S2. Expression of RegIV in mRNA and protein levels. (A) Elevated expression of RegIV mRNA in nine GC cell lines compared with GES-1 determined by qRT-PCR. Data are shown as $-\Delta \Delta C t$ values ( ${ }^{*} P<0.05$, ${ }^{* * P}<0.01$, $\left.{ }^{* *} P<0.001\right)$. GAPDH was used for normalization. (B) Elevated expression of RegIV protein in nine GC cell lines compared to GES-1 determined by ELISA. Data are shown as mean \pm S.D. of three independent experiments $\left({ }^{*} \mathrm{P}<0.05\right.$, ${ }^{* *} \mathrm{P}<0.01$, ${ }^{* * *} \mathrm{P}<0.001$ ).

Additional file 3: Figure S3. miR-24 targeted RegIV in SNU-16. (A) miR-24 expression in SNU-16 cells was effectively elevated by transient transfection of miR-24 (miR-24 mimics), while no statistical difference by anti-miR-24 (miR-24 inhibitor) as detected by qRT-PCR (**P $<0.01)$. (B) miR-24 mimics downregulated activity of a luciferase reporter containing wild-type RegIV 3'UTR (***P $<0.001$ ), but not the reporter with mutant RegIV 3'UTR. (C) Anti-miR-24 had no statistical difference on luciferase activity of wild-type or mutant Luc-RegIV. Data are shown as mean \pm S.D. of three independent experiments.

Additional file 4: Figure S4. miR-24 downregulated c-MYC expression in GC cell. (A) miR-24 downregulated c-MYC mRNA level in SGC-7901 and SNU-16. Data are shown as mean \pm S.D. of three independent experiments (**P <0.01). (B) miR-24 downregulated c-MYC and RegIV protein levels in SGC-7901 and SNU-16.

\section{Competing interests}

The authors declare that they have no competing interests.

\section{Authors' contributions}

YD, LH, MY, QY, BL, YY, CL, LS, MX and ZZ conceived and designed the experiments. YD, JL, BY, BL and LH performed the experiments. YD, LH and $\mathrm{BL}$ analyzed the data. YD, QY and BL wrote the manuscript. All authors read and approved the final manuscript.

\section{Acknowledgements}

This study was supported by grants from the National Natural Science Foundation of China (No. 81272749, No. 81172324, No. 91229106), Science and Technology Commission of Shanghai Municipality (No. 11441902100, No. 12XD1403700, No. 13ZR1425600), Key Projects in the National Science \& Technology Pillar Program of China No. 2014BAl09B03 and Research Fund for the Doctoral Program of Higher Education of China No. 20110073110071.

Received: 20 January 2014 Accepted: 20 May 2014

Published: 28 May 2014

\section{References}

1. Jemal A, Bray F, Center MM, Ferlay J, Ward E, Forman D: Global cancer statistics. CA Cancer J Clin 2011, 61:69-90.

2. Bartel DP: MicroRNAs: genomics, biogenesis, mechanism, and function. Cell 2004, 116:281-297.

3. Qin W, Shi Y, Zhao B, Yao C, Jin L, Ma J, Jin Y: miR-24 regulates apoptosis by targeting the open reading frame (ORF) region of FAF1 in cancer cells. PLoS One 2010, 5:e9429.

4. Bullock MD, Sayan AE, Packham GK, Mirnezami AH: microRNAs: critical regulators of epithelial to mesenchymal (EMT) and mesenchymal to epithelial transition (MET) in cancer progression. Biol Cell 2012, 104:3-12. 
5. Tzur G, Levy A, Meiri E, Barad O, Spector Y, Bentwich Z, Mizrahi L, Katzenellenbogen M, Ben-Shushan E, Reubinoff BE, Galun E: microRNA expression patterns and function in endodermal differentiation of human embryonic stem cells. PLoS One 2008, 3:e3726.

6. Ambros $\mathrm{V}$ : The functions of animal microRNAs. Nature 2004, 431:350-355.

7. Esquela-Kerscher A, Slack FJ: Oncomirs-microRNAs with a role in cancer. Nat Rev Cancer 2006, 6:259-269.

8. Zheng YS, Zhang $H$, Zhang XJ, Feng DD, Luo XQ, Zeng CW, Lin KY, Zhou H, Qu LH, Zhang P, Chen YQ: miR-100 regulates cell differentiation and survival by targeting RBSP3, a phosphatase-like tumor suppressor in acute myeloid leukemia. Oncogene 2012, 31:80-92.

9. Mattiske S, Suetani RJ, Neilsen PM, Callen DF: The oncogenic role of miR-155 in breast cancer. Cancer Epidemiol Biomarkers Prev 2012, 21:1236-1243.

10. Malleter $M$, Jacquot C, Rousseau B, Tomasoni C, Juge M, Pineau A, Sakanian V, Roussakis C: miRNAs, a potential target in the treatment of non-small-cell lung carcinomas. Gene 2012, 506:355-359.

11. Hou YY, Cao WW, Li L, Li SP, Liu T, Wan HY, Liu M, Li X, Tang H: microRNA-519d targets MKi67 and suppresses cell growth in the hepatocellular carcinoma cell line QGY-7703. Cancer Lett 2011, 307:182-190.

12. Li Z, Gu X, Fang Y, Xiang J, Chen Z: microRNA expression profiles in human colorectal cancers with brain metastases. Oncol Lett 2012, 3:346-350.

13. Tsukamoto $Y$, Nakada C, Noguchi T, Tanigawa M, Nguyen LT, Uchida T, Hijiya N, Matsuura K, Fujioka T, Seto M, Moriyama M: microRNA-375 is downregulated in gastric carcinomas and regulates cell survival by targeting PDK1 and 14-3-3zeta. Cancer Res 2010, 70:2339-2349.

14. Lu Z, Getz G, Miska EA, Alvarez-Saavedra E, Lamb J, Peck D, Sweet-Cordero A, Ebert BL, Mak RH, Ferrando AA, Downing JR, Jacks T, Horvitz HR, Golub TR: microRNA expression profiles classify human cancers. Nature 2005, 435:834-838.

15. Mendell JT, Olson EN: microRNAs in stress signaling and human disease. Cell 2012, 148:1172-1187.

16. Ueda T, Volinia S, Okumura H, Shimizu M, Taccioli C, Rossi S, Alder H, Liu CG, Oue N, Yasui W, Yoshida K, Sasaki H, Nomura S, Seto Y, Kaminishi M, Calin GA, Croce CM: Relation between microRNA expression and progression and prognosis of gastric cancer: a microRNA expression analysis. Lancet Oncol 2010, 11:136-146.

17. Wu WK, Lee CW, Cho CH, Fan D, Wu K, Yu J, Yu JJ, Sung JJ: microRNA dysregulation in gastric cancer: a new player enters the game. Oncogene 2010, 29:5761-5771

18. Li X, Zhang Y, Zhang Y, Ding J, Wu K, Fan D: Survival prediction of gastric cancer by a seven-microRNA signature. Gut 2010, 59:579-585.

19. Mishra PJ, Song B, Mishra PJ, Wang Y, Humeniuk R, Banerjee D, Merlino G, Ju J, Bertino JR: miR-24 tumor suppressor activity is regulated independent of p53 and through a target site polymorphism. PLoS One 2009, 4:e8445.

20. Lal A, Navarro F, Maher CA, Maliszewski LE, Yan N, O'Day E, Chowdhury D, Dykxhoorn DM, Tsai P, Hofmann O, Becker KG, Gorospe M, Hide W, Lieberman J: miR-24 Inhibits cell proliferation by targeting E2F2, MYC, and other cell-cycle genes via binding to "seedless" 3'UTR microRNA recognition elements. Mol Cell 2009, 35:610-625.

21. Xu Y, Zhao F, Wang Z, Song Y, Luo Y, Zhang $X$, Jiang L, Sun Z, Miao Z, Xu H: microRNA-335 acts as a metastasis suppressor in gastric cancer by targeting Bcl-w and specificity protein 1. Oncogene 2012, 31:1398-1407.

22. Tie J, Pan Y, Zhao L, Wu K, Liu J, Sun S, Guo X, Wang B, Gang Y, Zhang Y, Li Q, Qiao T, Zhao Q, Nie Y, Fan D: miR-218 inhibits invasion and metastasis of gastric cancer by targeting the Robo1 receptor. PLoS Genet 2010, 6:e1000879.

23. Li Z, Cao Y, Jie Z, Liu Y, Li Y, Li J, Zhu G, Liu Z, Tu Y, Peng G, Lee DW Park SS: miR-495 and miR-551a inhibit the migration and invasion of human gastric cancer cells by directly interacting with PRL-3. Cancer Lett 2012, 323:41-47

24. Bader AG, Brown D, Stoudemire J, Lammers P: Developing therapeutic microRNAs for cancer. Gene Ther 2011, 18:1121-1126.

25. Kota J, Chivukula RR, O'Donnell KA, Wentzel EA, Montgomery CL, Hwang HW, Chang TC, Vivekanandan P, Torbenson M, Clark KR, Mendell JR, Mendell JT: Therapeutic microRNA delivery suppresses tumorigenesis in a murine liver cancer model. Cell 2009, 137:1005-1017.

26. Xie L, Wang T, Yu S, Chen X, Wang L, Qian X, Yu L, Ding Y, Zhang C, Liu B: Cell-free miR-24 and miR-30d, potential diagnostic biomarkers in malignant effusions. Clin Biochem 2011, 44:216-220.
27. Lin SC, Liu CJ, Lin JA, Chian WF, Hung PS, Chang KW: miR-24 up-regulation in oral carcinoma: positive association from clinical and in vitro analysis. Oral Oncol 2010, 46:204-208.

28. Liu X, Wang A, Heidbreder CE, Jiang L, Yu J, Kolokythas A, Huang L, Dai Y, Zhou $X$ : microRNA-24 targeting RNA-binding protein DND1 in tongue squamous cell carcinoma. FEBS Lett 2010, 584:4115-4120.

29. Chen X, Ba Y, Ma L, Cai X, Yin Y, Wang K, Guo J, Zhang Y, Chen J, Guo X, Li Q, Li X, Wang W, Zhang Y, Wang J, Jiang X, Xiang Y, Xu C, Zheng P, Zhang J, Li R, Zhang H, Shang X, Gong T, Ning G, Wang J, Zen K, Zhang J, Zhang $\mathrm{CY}$ : Characterization of microRNAs in serum: a novel class of biomarkers for diagnosis of cancer and other diseases. Cell Res 2008, 18:997-1006.

30. Cao M, Seike M, Soeno C, Mizutani H, Kitamura K, Minegishi Y, Noro R, Yoshimura A, Cai L, Genma A: miR-23a regulates TGF-beta-induced epithelial-mesenchymal transition by targeting E-cadherin in lung cancer cells. Int J Oncol 2012, 41:869-875.

31. To KH, Pajovic S, Gallie BL, Thériault BL: Regulation of p14ARF expression by miR-24: a potential mechanism compromising the $\mathrm{p} 53$ response during retinoblastoma development. BMC Cancer 2012, 12:69.

32. Wu J, Zhang YC, Suo WH, Liu XB, Shen WW, Tian H, Fu GH: Induction of anion exchanger-1 translation and its opposite roles in the carcinogenesis of gastric cancer cells and differentiation of K562 cells. Oncogene 2010, 29:1987-1996.

33. Lewis $B P$, Burge $C B$, Bartel DP: Conserved seed pairing, often flanked by adenosines, indicates that thousands of human genes are microRNA targets. Cell 2005, 120:15-20.

34. Hartupee JC, Zhang H, Bonaldo MF, Soares MB, Dieckgraefe BK: Isolation and characterization of a CDNA encoding a novel member of the human regenerating protein family: RegIV. Biochim Biophys Acta 2001, 1518:287-293.

35. Oue N, Hamai Y, Mitani Y, Matsumura S, Oshimo Y, Aung PP, Kuraoka K, Nakayama H, Yasui W: Gene expression profile of gastric carcinoma: identification of genes and tags potentially involved in invasion, metastasis, and carcinogenesis by serial analysis of gene expression. Cancer Res 2004, 64:2397-2405.

36. Zheng HC, Xu XY, Yu M, Takahashi H, Masuda S, Takano Y: The role of ReglV gene and its encoding product in gastric carcinogenesis. Hum Pathol 2010, 41:59-69.

37. Kuniyasu H, Oue N, Sasahira T, Yi L, Moriwaka Y, Shimomoto T, Fujii K,

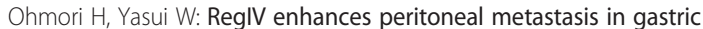
carcinomas. Cell Prolif 2009, 42:110-121

38. Miyagawa K, Sakakura C, Nakashima S, Yoshikawa T, Fukuda K, Kin S, Nakase Y, Shimomura K, Oue N, Yasui W, Hayasizaki H, Okazaki Y, Yamagishi H, Hagiwara A, Otsuji E: Overexpression of RegIV in peritoneal dissemination of gastric cancer and its potential as a novel marker for the detection of peritoneal micrometastasis. Anticancer Res 2008, 28:1169-1179.

39. Moon JH, Fujiwara Y, Nakamura Y, Okada K, Hanada H, Sakakura C, Takiguch S, Nakajima K, Miyata H, Yamasaki M, Kurokawa Y, Mori M, Doki Y: RegIV as a potential biomarker for peritoneal dissemination in gastric adenocarcinoma. J Surg Oncol 2012, 105:189-194.

40. Mitani Y, Oue N, Matsumura S, Yoshida K, Noguchi T, Ito M, Tanaka S, Kuniyasu H, Kamata N, Yasui W: RegIV is a serum biomarker for gastric cancer patients and predicts response to 5-fluorouracil-based chemotherapy. Oncogene 2007, 26:4383-4393.

41. Klein CA: Cancer. The metastasis cascade. Science 2008, 321:1785-1787.

42. Nicoloso MS, Spizzo R, Shimizu M, Rossi S, Calin GA: microRNAs-the micro steering wheel of tumour metastases. Nat Rev Cancer 2009, 9:293-302.

doi:10.1186/1476-4598-13-127

Cite this article as: Duan et al:: Tumor suppressor miR-24 restrains gastric cancer progression by downregulating RegIV. Molecular Cancer 2014 13:127. 